\title{
Inhotim. Tunga. True Rouge.
}

\author{
ANDRÉ MAYA MONTEIRO
}

\section{Resumo}

Este artigo analisa a instalação True Rouge, do artista Tunga, a partir de sua montagem, que se encontra em Inhotim. Verificam-se aqui alguns dos procedimentos recorrentes, e particulares, que o artista emprega nesse trabalho, com a finalidade de localizá-lo no corpus da obra do artista. Para tanto, além da análise formal da obra propriamente dita, foram estudadas algumas relações entre o trinômio artista obra - museu.

Palavras-chave:

Arte contemporânea. Tunga. True Rouge. 


\title{
Inhotim. Tunga. True Rouge.
}

\author{
ANDRÉ MAYA MONTEIRO
}

Abstract

This article examines the art installation True Rouge, by the artist Tunga, from its assembly which is in Inhotim. Here there are some of the recurrent procedures, and individualities, which the artist employs in this work, in order to locate it in the corpus of the artist's work. For this

Keywords: Contemporary Art. reason, beyond the formal analysis of the work itself, we Tunga. True Rouge. studied some relationships between the triad artist - work museum. 
Quando adentramos em um ambiente, seja ele familiar ou hostil, prescrutamos à nossa volta em busca de informações. No entanto, o tipo de informação que desejamos apreender é situacional e demasiadamente variada. Talvez, a única constante, dentre o universo de possibilidades de interpretação de um determinado cenário, seja a identificação da presença ou ausência de outrem. Olhar a garrafa de vinho aberta sobre mesa, ouvir o som do toca-discos ligado, sentir o cheiro de perfume próximo à penteadeira. Os índices, porém, não necessariamente indicam a presença humana naquele exato momento. A cena de um crime não é o crime acontecendo aqui e agora; as pistas é que permitem a reconstituição do que ocorreu em um dado momento pretérito. Talvez os vestigíos possam dizer mais sobre um protagonista do que a sua presença.

Mas afinal, quem são os protagonistas de True Rouge (1997), obra do artista carioca Antonio José de Barros Carvalho e Mello Mourão [1952 - ], mais conhecido pela alcunha de Tunga, que se encontra no Centro de Arte Contemporânea Inhotim?

True Rouge é uma das obras mais espetaculares do artista. Nela podemos encontrar uma série de procedimentos recorrentes no trabalho de Tunga, e ainda, observar suas particularidades, os elementos que a tornam singular. No entanto, além das qualidades intrínsecas da obra, sua visibilidade é assegurada, em muitos casos, por critérios que extrapolam seu valor estético (OLIVEIRA, 2010). Por isso, sua contextualização, no espaço e no tempo, traz à tona certos elementos que nos permitem compreender com maior profundidade sua relevância no corpus da obra do artista. Para tanto, o presente artigo pretende analisar a obra propriamente dita e também articular algumas das possíveis relações entre o trinômio artista - obra - museu; essa análise é pertinente para uma melhor compreensão da instalação, bem como da sua importância e visibilidade. 
Sobre a criação da obra em questão, Tunga, em entrevista à Folha de São Paulo, declarou: "é uma peça que nasceu junto, quase que, simultaneamente, com um poema do Simon Lane, que é um escritor inglês, com quem eu colaborei já largamente. $\mathrm{O}$ fato desse poema estar na gênese da obra faz dele não só um poema, mas quase matéria-prima" (TUNGA, 2007, p. 4). Desde então, True Rouge já assumiu diversas versões, em diferentes espaços, entre os quais destacam-se: Pensatorium (Rio de Janeiro, Brasil - 1997), Luhring Augustine Gallery (Nova Iorque, Estados Unidos - 1998), Bienal do Mercosul (Porto Alegre, Brasil - 1999) e Jeu de Paume (Paris, França - 2001). Para cada um desse ambientes, Tunga trabalhou com artistas performáticos onde um ritual inaugurou a obra. Para descrever esse procedimento, recorrente em seus trabalhos, Tunga conceituou o termo instauração, palavra que prefere à performance ou instalação. Segundo ele, a nomeclatura designa de maneira mais satisfatória algo que, a partir de um momento, começa a existir, se torna verdadeiro, instaura um mundo (ROLNIK, 1998).

Hoje, uma das versões de True Rouge ocupa um pavilhão exclusivo em Inhotim, museu privado situado nos arredores da cidade de Brumadinho, Minas Gerais, Outras obras do mesmo artista também compõem o acervo do museu, a saber: Ão (1980), Sem título (série Vanguarda Viperina, 19831997); Lézart (1989); Palíndromo Incesto (1990-1992); Deleite (1999) e A Bela e a Fera (2001). Das obras supracitadas, somente Lézart e True Rouge estão em exposição permanente. Recentemente, foi noticiado pela imprensa, que em 2012 será inaugurado, em Inhotim, um novo pavilhão de dois mil metros quadrados para o artista (VELASCO, 2011). Nada foi declarado, no que se refere às obras do artista que vão habitar esse novo espaço. No entanto, levando-se em consideração a dimensão do ambiente e a relação estreita entre artista e instituição, é provável que o artista realize um projeto original pensado para o ambiente, em diálogo com o espaço, site-specific, ou seja, uma obra inédita.

O interesse dessa instituição pelo trabalho de Tunga faz parte da própria trajetória do museu. Foi Tunga, em 1998, quem aconselhou o proprietário do museu, com quem tem um relação de amizade, o empresário do ramo siderúrgico Bernardo Paz [1949 - ], a investir em arte contemporânea. O primeiro pavilhão construído por Bernardo Paz, não coincidentemente, abrigava um trabalho do artista, True Rouge, que acabou por se tornar também a primeira obra a compor o 
acervo do museu, quando o empresário decidiu partilhar sua coleção privada, transformando-a na base do novo museu. Braga (2009) localiza nas obras de Tunga e de Cildo Meireles os dois eixos conceituais que norteiam a constituição do acervo de Inhotim. Ainda segundo o autor (2009), a obra de Inhotim que se articula conceitualmente de maneira mais profícua com True Rouge é O desvio para o vermelho, de Cildo Meireles [1948 - ]. O vermelho de Tunga é mítico, uma verdade inventada, e o de Cildo transita entre o estético e o político, um desvio para a esquerda. Por último, o autor comenta que faltam interlocutores para as obras desses dois artistas, na coleção, que ainda carece de coerência artística e crítica, ou ainda, de uma política curatorial coesa, o que reduz as possibilidades de diálogo entre os trabalhos que constituem o acervo do museu. Em discordância com Braga, Jochem Voltz' ${ }^{1}$ curador e diretor artístico de Inhotim, afirma que as mostras do museu buscam primordialmente a multiplicidade de linguagens e a criação de diálogos entre as obras (SEBASTIÃO, sem data).

Apesar das possíveis lacunas na coleção apontadas por alguns críticos, Inhotim se tornou um dos mais importantes museus de arte contemporânea do país. Seu colossal terreno, de mais de 2.100 hectares, compreende cerca de 500 obras de 100 artistas, entre estrangeiros e brasileiros, todas produzidas a partir da década de 1960, abrangendo diversos formatos e meios (escultura, instalação, pintura, desenho, fotografia, filme e vídeo), nem todas em exibição. Entre os respresentantes brasileiros, podemos destacar: Adriana Varejão, Nuno Ramos, Hélio Oiticica, Waltercio Caldas, Artur Barrio, Miguel Rio Branco, Ernesto Neto, Vik Muniz e Amilcar de Castro.

Ainda merece destaque, o fato de que algumas das obras de Inhotim foram criadas especialmente para o museu, site-specific, estratégia que vem sendo utilizada pela equipe curatorial da instituição. Essa diretriz fica clara nos dizeres de Rodrigo Moura, curador do museu: "Conquistamos padrão de excelência e credibilidade no que se refere ao trabalho com arte. A possibilidade de construir um local especialmente para abrigar uma obra, de financiar o projeto, inserindo-o em contexto significativo, interessa a todos os artistas" (apud SEBASTIÃO, sem data). Finalmente, vale destacar que Inhotim abriga também um jardim botânico, um polo gastronômico e, em breve, estará inaugurando um complexo residencial e hoteleiro. Bernardo Paz ainda prevê, para os próximos cinco anos, a construção de um teatro, um centro de convenções e um centro comercial com lojas de grife (VELASCO, 2011). O 
proprietário do museu ainda declarou que pretende "criar um lugar para onde as pessoas possam vir e trabalhar sem pressa, viver com os pássaros, se divertir, trazer a vida para cá. É como a Disney, que começou como um parque e depois se expandiu. Mas aqui a coisa é séria" (PAZ apud VELASCO, 2011, p. 1).

É notório que Tunga, artista multimidiático, com incursões em desenho, escultura, instalação, filme, vídeo e performance, tem ocupado um espaço privilegiado na arte contemporânea nos últimos dez anos. Nascido em 1952, Tunga é filho do jornalista e poeta Gerardo Mello Mourão. O artista teve seu primeiro contato com a arte na casa de seu avô paterno, colecionador de arte moderna e barroca, o deputado federal e posteriormente senador Antonio de Barros Carvalho, no Rio de Janeiro, que era freqüentada por artistas como Portinari, Manuel Bandeira, Guignard etc. Iniciou sua carreira artística em meados dos anos 1970, enquanto ainda era estudante de graduação do curso de Arquitetura da Universidade Santa Úrsula, no Rio de Janeiro. Logo após a formatura, o artista mudou-se para Paris, onde residiu por dois anos, e abandonou a arquitetura definitivamente; lá passou a se dedicar à arte integralmente. Teve sua primeira mostra individual no Museu de Arte do Rio de Janeiro (MAM), em 1974. Quando voltou ao Brasil, no final da década de 1970, encontrou seus pares: Waltércio Caldas [1946 - ], Cildo Meirelles [1948 - ], Zé Resende [1945 - ], Ronaldo Brito [1949 - ]. A partir do início da década de 1980, começou a galgar uma carreira internacional com destaque para as exposições na Bienal de Veneza (1981), na Itália; na Bienal de São Paulo (1987, 1994 e 1998), no Brasil; no Museu Stedelijk (1989), na Holanda; na galeria Jeu de Paume (1992), na França; e no MOMA (1993), nos Estados Unidos.

Apesar de sua trajetória artística remeter ao final da década de 1970, entre o neoconcretismo e a geração de artistas surgidos na década de 1980, o ano mais marcante em sua carreira talvez tenha sido o de 1997, quando sua exposição na $10^{\underline{a}}$ Documenta (Kassel, Alemanha) teve grande repercussão no circuito internacional. True Rouge também data desse mesmo período. Ainda em 1997, lança pela editora Cosac Naify o livro Barroco de Lírios, livro inaugural da casa editorial. Dez anos mais tarde, precisamente em 2007, o artista é convidado para um projeto comemorativo de dez anos da editora, quando lançam uma obra de circulação restrita com tiragem de apenas 500 exemplares, assinados pelo artista, e que não foi comercializada; foi doada a bibliotecas, museus e instituições culturais nacionais e estrangeiras. A Caixa de Livros Tunga, 
como foi batizada, foi concebida pelo próprio artista e é formada por sete volumes (seis livros e um cartaz), com distintos formatos, unidos por uma caixa imantada. O conjunto é constituído pelos seguintes volumes: Olho por olho, Encarnações miméticas, Se essa rua fosse minha, Lúcido Nigredo, Prole do bebê, True Rouge e o Cartaz Louvre. Nesse caso, True Rouge ganha uma releitura poética através de uma série de montagens sequenciais que, de maneira quase cinematográfica, criam uma narrativa própria, para além da obra registrada, e onde momentos efêmeros se cristalizam.

Tunga tem predileção por mistérios, tanto na vida quanto na arte. Os dados biográficos disponíveis sobre o artista são vastos, no entanto, muitas vezes imprecisos. O local de nascimento, por exemplo, foi recentemente declarado como sendo Rio de Janeiro, como supracitado; no entanto, em muitas publicações é referido como sendo em Palmares, Pernambuco ${ }^{2}$. A esse respeito, Tunga declarou:

Retemos os fatos da nossa vida a partir de uma idade tenra, mas já longe daquela do nascimento. Então, acreditamos que nascemos em um lugar porque algum documento atesta, ou porque alguém te conta, ou porque você vai investigar por meio de fontes diversas. Eu fui investigar onde tinha nascido porque não me lembrava. E essa investigação me levou a testemunhos e a documentos. Eu deparei com documentos de nascimento em dois lugares diferentes na mesma hora, no mesmo momento: Palmares, em Pernambuco, e Rio de Janeiro [...] Sabendo que, na minha primeira infância, a minha mãe e a minha tia eram gêmeas idênticas, suspeitei que algum tipo de alteração genética tivesse se operado e eu tivesse, efetivamente, nascido em dois lugares e eles se juntaram depois. Acho que venho tentando exercer essa capacidade de me juntar depois, de juntar não só os Tungas que podem ter nascido separados, mas a pluralidade de Tungas e a pluralidade de sujeitos que constituem o meu sujeito [...] A história que acabo de contar das duas certidões é mentira minha. Há algumas histórias que foram inventadas, como a que eu nasci em Palmares, e até hoje continuam sendo reproduzidas. Mas minha família é realmente de Pernambuco e foi morar no Rio de Janeiro (TUNGA, 2010, p. 5).

Essa mesma atitude torna-se procedimento artístico quando Tunga apresenta, em suas obras, informações pseudocientifícas tiradas de sua cartola, de seu imaginário. Lindo- 
te (2005) comenta que a obra ficcional do artista cria um emaranhado proveniente de diferentes postulações filosóficas, da ciência e da pseudociência, da teologia e da religiosidade. A autora ainda destaca que grande parte da obra de Tunga é representada por narrativas elaboradas a partir de referências textuais diversas, tais como: documentos, recortes de jornais, relatórios de pesquisa, falsas inscrições ou achados arqueológicos, são, em sua grande maioria, simulações de uma suposta verdade científica.

Tunga também evita analisar seu próprio trabalho. Talvez porque acredite que explicar a própria obra tenha um efeito reducionista, e, por isso, tem pouco a dizer sobre o próprio trabalho; considera que o seu trabalho é que tem muito a dizer. Ao comentar sobre a artista francesa Louise Bourgeois ${ }^{3}$, o artista demonstra sua admiração pela obra de Bourgeois, mas diz que as declarações da artista misturam obra e biografia, o que faz gerar interpretações rasas por parte do espectador. Em suas próprias palavras:

Gosto muito do trabalho dela. Mas repare na imensa quantidade de textos que relacionam suas obras com sua vida pessoal. Repare também no esforço dela em relatar os traumas que sofreu. Bourgeois criou uma hermenêutica que nos ajuda a conviver com suas obras, mas que dificulta um entendimento mais profundo do que produziu. Quero evitar esse vício de olharem para uma peça minha e concluírem que a fiz porque algo aconteceu comigo. (TUNGA apud MORESCHI, 2010)

Por isso, Tunga adota essa espécie de notório anonimato. Dá entrevistas, faz declarações, mas pouco esclarece. Quando o artista foi questionado sobre a suposta conexão entre sua obra Xifópagas Capilares (1985) e a pintura As Gêmeas (1940), de Guignard, negou a possível relação entre as duas obras e declarou que "dar essa informação às pessoas seria entregar o peixe fácil demais" (TUNGA apud MORESCHI, 2010). Porém, confirma que sua mãe e sua tia, irmãs gêmeas, serviram de modelo para a celebrada pintura de Guignard. Talvez essa seja uma postura tropicalista, como a da popular música de Tom Zé intitulada Tô, cujos versos dizem: "Eu tô te explicando / Prá te confundir / Eu tô te confundindo / Prá te esclarecer / Tô iluminado / Prá poder cegar / Tô ficando cego / Prá poder guiar".

Recentemente, Tunga teve exposições individuais em alguns espaços prestigiados da arte contemporânea, como a 
Pirâmide do Louvre (2005), em Paris, e o MoMA PS-1 (2007), em Nova Iorque. O próprio artista reconhece um crescente interesse por sua obra e de seus compatriotas; porém, não aceita a pecha de artista brasileiro. Segundo ele, a ideia de artista brasileiro lhe dá arrepios, assim como a ideia de artista americano ou europeu (TUNGA, 2010). No entanto, Tunga declarou: "O que o Brasil nos dá como subsídios em termos culturais é obviamente a sua diversidade, a sua heterogeneidade, a possibilidade do exercício de práticas as mais diversas, de linguagens as mais diversas, que vão produzir a forma dita artística. Dificilmente um artista europeu dispõe de uma tal riqueza de experiências e linguagens culturais que lhe proporcionem uma obra mais completa" (TUNGA apud ROLNIK, 1998, p.125). Essa aparente contradição se resolve no dizeres de Rolnik:

Assumir e reafirmar a ética antropofágica como legado da tradição brasileira, é descartar qualquer idéia de identidade nacional. À primeira vista, isto pode parecer paradoxal, mas não o é se entendermos que, pensando nestes termos, o que rege a formação das obras de cultura e de existência no país, é exatamente a mistura. Não uma mistura que faria nascer novas identidades, agora mestiças, mas uma incansável e variada mistura, que implica sempre em devir-outro. Assim, regidos por aquilo que tenho chamado de 'princípio antropofágico de individuação', os brasileiros tenderiam a não caracterizar-se por qualquer espécie de representação substancializada de si, para serem, ao contrário, aquilo que constantemente os separa de si mesmos, seja qual for o contorno da auto imagem em funcionamento e por mais sedutora que ela se apresente (idem, p. 124).

Se a produção artistica contemporânea, internacionalmente, vem sendo caracterizada, por alguns autores, como uma arte radicante, em nosso contexto particular, o Brasil, essa já é uma realidade vivenciada há algum tempo. Afinal, o que é ser radicante? Segundo Borriaud, é "pôr em cena, pôr em andamento as próprias raízes, em contextos e formatos heterogêneos; negar-lhes a virtude de definir por completo a nossa identidade; traduzir as ideias, transcodificar as imagens, transplantar os comportamentos, trocar mais do que impor" (2011, p.20). Ao articularmos as palavras de Rolnik e Borriaud, podemos especular que a herança antropofágica brasileira acabou por tornar uníssonas a produção artística 
local e a produção artística internacional. Essa poderia ser uma explicação para o espaço que artistas como Tunga, Cildo Meireles e Waltercio Caldas, cujas trajetórias remetem a mais de trinta anos de produção intensa, para citar apenas alguns, têm progressivamente conquistado junto a diversas instituições no país e no exterior.

True Rouge é mais um representante dessa safra, envelhecida em tonel de carvalho e muito saborosa. A instalação encontra-se em uma casa, galeria, circundada por uma natureza, de certo, exuberante à beira de um lago. Próximo à fachada da edificação, andando em direção à entrada da casa, podemos ver, através de painéis de vidro, uma sala onde uma enorme trama de redes vermelhas $(1315 \times 750$ x $450 \mathrm{~cm}$ - montagem de Inhotim) suspende uma série de objetos. Todavia, a visão que temos da fachada não é suficiente para identificarmos com precisão que objetos são esses e como estão dispostos. Esse é o convite perfeito para o invasor: a curiosidade. Garrafas, cálices, funis de vidro soprado, esponjas do mar, panos de feltro, escovas de garrafa, contas de vidro, bolas de bilhar, esferas de vidro, fluidos de cor avermelhada - "insólito equipamento" (ROLNIK, 1998, p.115). Em alguns pontos, o fluido avermelhado que ocupava os recipientes de vidro pendentes escorreu e caiu no chão formando poças, rastros que parecem de sangue.

As redes vermelhas são presas a várias cruzetas que, por sua vez, são fixadas ao teto. Os objetos encontram-se aleatoriamente distribuídos pelas redes. Na composição, o peso exercido em cada conjunto é diferente e, por conseguinte, as alturas são variáveis em função da quantidade de elementos contidos no conjunto que estamos observando, sendo que, em alguns casos, a rede quase toca o chão e, em outros, flutua. A estrutura, que se assemelha a um sistema nervoso, é aparentemente frágil, mas suficiente para suportar a pressão. A distribuição das redes na sala segue uma ordem: do centro, área de maior densidade, para a periferia, área de menor densidade (TUNGA, 2007). A obra, em sua totalidade, forma uma enorme escultura vermelha suspensa, onde prevalecem certas tensões. Um mundo regido por uma trama enraizada em diversos pontos, onde a tessitura gera ramificações e conecta múltiplos elementos, em uma perfeita imagem de uma raiz, que gera múltiplos significados, múltiplas conexões. Segundo o crítico Paul Sztulman, a polissemia é uma das características que permeiam a obra do artista, e pontua que: 
Freqüentemente lidando com o excesso - muitas de suas obras foram realizadas através do acúmulo de materiais pesados (ferro, cobre, imã) - Tunga apresenta objetos comuns que passaram por uma estranha transformação: dedais, agulhas gigantes ou pentes. Inventa um bestiário fantástico de lagartos e serpentes mutantes que parece saído diretamente de uma antologia surrealista. Jogando com as diferenças de proporções, Tunga considera a escultura um conjunto de formas enigmáticas cuja estranheza e proporções fabulosas intrigam o espectador e causam transtorno em sua percepção habitual de próximo e distante, dentro e fora, cheio e vazio" (1997, p. 226).

True Rouge, como já foi dito anteriormente, foi criado quase simultaneamente com o poema algébrico, de mesmo nome, pelo escritor Simon Lane. O texto apresenta uma estranha matemática mística que, à maneira da alquimia, leva a uma profusão do vermelho pelo espaço, o vermelho que invade o ambiente. Em entrevista a Simon Lane, para a revista Bomb Magazine, Tunga foi questionado sobre a teoria que utiliza em seu trabalho; em réplica disse, tergiversando: "teoria e arte são a mesma coisa para mim. A teoria da teoria é uma arte possível: um poema cria a possibilidade de um poema possível. Em outras palavras, cria a teoria do poema. O exercício de escrever um poema é apenas uma das versões teóricas deste poema" (2002). Portanto, essas versões seriam como fábulas, onde o artista cria um universo próprio, um microcosmo. Um universo em que o artista cria verdades inventadas, característica recorrente em sua obra (BRAGA, 2009). Esse mundo inventado é habitado por materiais e objetos heteróclitos, que fazem emergir uma poética individual com fortes laços surrealistas (CHIARELLI, 2002). Um universo em equilíbrio instável, que pende para o chão, mas, misteriosamente, flutua.

Feita essa breve descrição do cenário, podemos reunir mais algumas informações. Afinal, a descrição pura e simples não circunscreve a narrativa que a obra oferta ao espectador. Mais do que a mera construção de um cenário, as peças de True Rouge evocam a presença de fantasmas. Os ausentes da obra de Tunga não são os ausentes à mesa da pintura de Chardin (HUSTVEDT, 1997); nem ao menos os ausentes da urbe fotografada por Atget (BENJAMIN, 2006). A mágica de Tunga, entretanto, é semelhante. Os alquimistas ainda estão presentes, mesmo que não estejam figurados. Para tanto, cabe ao 
procedimento da instauração conferir à obra essa dimensão. A esse respeito, Marta Martins Lindote nos diz que:

O termo "instauração", conceituado pelo artista, tenta formular uma aliança entre as categorias de "ação", que é relativo às performances no domínio das artes plásticas das vanguardas tardias; e de "instalação", que usualmente constitui-se como uma espécie de montagem de objetos bi ou tridimensionais, dentro de um determinado espaço, fato que gera uma inclusão pensada e/ou calculada do espaço circundante e do próprio espectador na mostra, e que é também uma categoria artística oriunda das vanguardas tardias do início dos anos 6o. Tunga alia estas duas categorias, criando um terceiro elemento, a "instauração", ao executar uma determinada performance e deixar os restos dessa ação, no ambiente. Nesse sentido, a "instalação" é pensada como resíduo, como dejeto dos objetos e materiais utilizados na "ação" precedente conjugados na "instauração" (2005, p. 27).

A instauração, portanto, conjuga duas ideias distintas: instalação, caráter de sua obra, e ação, performance que ativa a obra e cria um mundo. Se a instauração é um momento, os seus vestigíos são perenes, como as manchas de sangue no chão em True Rouge. O espectador de olhar aguçado consegue perceber alguns desses elementos no momento de fruição, e a aparente fugacidade do rito se presentifica por meio dessas marcas. Na instauração de True Rouge, em Inhotim, artistas nus e o público interagiram com os elementos e realizaram essa metamorfose que a fórmula de Simon Lane propõe. Os elementos, objetos constitutivos da obra, foram reorganizados, algumas vezes ao acaso, em um longo improviso, que acrescenta à composição uma característica singular, onde o projeto de Tunga implica em uma sucessão de fatos que transforma espontaneamente o seu trabalho. Posteriormente, a tentativa de retomar esse momento fugidio permite uma multiplicidade de interpretações, mistérios indecifráveis que reativam a fábula. Essa é a natureza morta de Tunga. E os mortos ainda falam. Dizem coisas muitas vezes incompreensíveis, em línguas mortas, e, nem por isso, menos significativas. O ritual de sangue transforma o espaço e nos transforma. Aos poucos, nos tornamos matéria prima da obra. Um mundo compartilhado onde as regras surgem, não são criadas. De acordo com Rolnik, "na fórmula de Tunga, o que o artista propõe, é um protocolo de experimentação - lista de objetos, 
roteiro de operações e, eventualmente, agentes humanos ou não de tais operações" (1998, p. 118).

Afinal, quem são os protagonistas de True Rouge? Somos todos nós. Os presentes e os ausentes. Os que realizaram procedimentos e os que buscam compreender esses gestos. E a cada nova busca os significados são ressignificados. A criação do moto perpétuo, transformação contínua do ser e da obra, é a verdadeira tarefa do artista, ambiciosa, porém, instigante.

\section{Referências}

BENJAMIN, Walter. Selected Writings. Volume 4: 1938-1940. Cambridge, Massachusetts \& London: Belknap Press of Harvard University Press, 2006.

BRAGA, Gedley Belchior. Através: Inhotim ama Luísa Strina e Fortes Vilaça. Belo Horizonte: Mediação, v. 9, 2009 p. 129142.

HUSTVEDT, Siri. Ghosts at the Table. London: Modern Painters, volume 10, number 2, 1997, p. 20 - 25.

LINDOTE, Marta Lúcia Pereira Martins. Entre a Grade e a Espiral: Sobre Algumas Narrativas Ficcionais de Tunga. Tese (Doutorado em Teoria Literária) - Universidade Federal de Santa Catarina (Ufsc), Florianópolis, 2005.

MORESCHI, Bruno. Dentes descabelados. São Paulo: Piauí (Online), número 49, outubro de 2010. Disponível em: $<$ http://revistapiaui.estadao.com.br/edicao-49/artesplasticas/dentes-descabelados > Acesso em: 19 de novembro de 2011.

OLIVEIRA, Emerson Dionisio Gomes de. Museus de fora: a visibilidade dos acervos de arte contemporânea no Brasil. Porto Alegre: Zouk, 2010.

ROLNIK, Suely. Instaurações de mundos. In: Tunga: 19771997. Curadoria de Carlos Basualdo. Miami: Museum of Contemporary Art, 1998, p. 115-136.

SZTULMAN, Paul. Tunga. In: Documenta 10. Kassel: Documenta, 1997, p. 226.

TUNGA. Tunga. Bombsite (Bomb Magazine), New York, 2002. Entrevista concedida a Simon Lane. Disponível em: <http://bombsite.com/issues/78/articles/2442 > Acesso em: 28 de outubro de 2011.

TUNGA. Leia entrevista com o artista plástico Tunga. Folha. com (Ilustrada), São Paulo, 21 de novembro de 2007. Entrevista concedida a Marcos Augusto Gonçalves. Disponí- 
vel em: < http://www1.folha.uol.com.br/folha/ilustrada/ ult9ou347005.shtml > Acesso em: 20 de outubro de 2011.

TUNGA. Olhar aguçado. São Paulo: Trip, número 194, p. 16 28, 2010. Entrevista concedida a Daniela Fernandes.

WALTER, Sebastião. A capital brasileira da arte contemporânea. Bravo!, São Paulo. Disponível em: < http://bravonline. abril.com.br/materia/a-capital-brasileira-da-arte-contemporanea-2? pagina=3 > Acesso em: 06 de novembro de 2011.

WALTER, Sebastião. Artistas jovens e veteranos terão obras apresentadas em mostra no Inhotim. Diário de Pernambuco, Recife. Disponível em: < http://www.diariodepernambuco.com.br/economia/nota.asp? materia $=20110821172832$ $>$ Acesso em: 15 de novembro de 2011.

VELASCO, Suzana. Bernardo Paz quer transformar museu de Inhotim em complexo de entretenimento e consumo. Rio de Janeiro: O Globo, Segundo Caderno, p.1, 8 de outubro de 2011.

\section{NOTAS}

1. A coleção de Inhotim está sob os cuidados de uma equipe de curadores formada pelo alemão Jochem Voltz, o brasileiro Rodrigo Moura e o norte-americano Allan Schwartzman.

2. Na tese de doutorado em Teoria Literária de Lindote (2005), cujo objeto de estudo é o trabalho de Tunga, o local de nascimento do artista é referido equivocadamente como sendo Palmares. A mesma referência errônea é multiplicada inúmeras vezes ao se pesquisar sobre biografia do artista, em especial na internet.

3. O trabalho de Tunga já foi comparado ao da artista, nos dizeres de Paul Ardenne: "Os contornos de um simbolismo sustentado sensível pode incomodar pelo aspecto anacrônico, para dizer fácil (esse é um ponto que explora, por exemplo, Louise Bourgeois, cujo objetivo é mais inteligível do que o do artista brasileiro)".

Recebido em: 10/12/11

Aceito em: 13/02/12 


\section{ANDRÉ MAYA MONTEIRO \\ andremayamonteiro@gmail.com}

Cursa Mestrado no Programa de Pós-Graduação em Artes da Universidade de Brasília, na linha Teoria e História da Arte, sob orientação do Prof. Dr. Emerson Dionisio Gomes de Oliveira. 